\title{
Some consequences of perinatal lesions of the visual cortex in the cat
}

\author{
ALLAN B. WETZEL2, VENAN E. THOMPSON ${ }^{3}$, JAMES A. HOREL`4 AND PATRICIA M. MEYER
} OHIO STATE UNIVERSITY

\begin{abstract}
Abstraet
Kittens with lesions of the visual cortex and their normal littermates were tested on visual placing responses and two measures of activity. These Ss were also compared on a pattern discrimination with normal cats and cats with visual ablations. Ss that had sustained the operation as infants learned the pattern habit as well as normal adult cats, but removal of visual neocortex severely retarded the performance of adult Ss.

\section{Problem}

The observation that infant animals show substantially more recovery following lesions of the central nervous system than do adult animals has been reported by a number of scientists using several species and several lesions (Kennard, 1942; Akert et al, 1959; Benjamin \& Thompson, 1959; Doty, 1961; Sharlock, Tucker, \& Strominger, 1963). With respect to visual pattern tasks, Lashley (1933), Smith (1938) and Horel et al (in press) have found that adult rats or cats with lesions of the visual cortex cannot learn certain pattern discriminations. Nevertheless, kittens subjected to the same lesion at two days of age were able to discriminate shapes (Doty, 1961). The present experiment was designed to investigate several visually dependent behaviors following visual ablations in cats and neonatal kittens.
\end{abstract}

\section{Method}

The Ss were 14 kittens from four litters and 17 adult cats. Infants were divided into two groups, so that at least one kitten from each litter was assigned to a visually decorticated Group VK, and one of its littermates served in the normal control Group NK. The adult cats were randomly assigned to Group VC, cats with lesions of the visual neocortex, or to Group NC, normal cats.

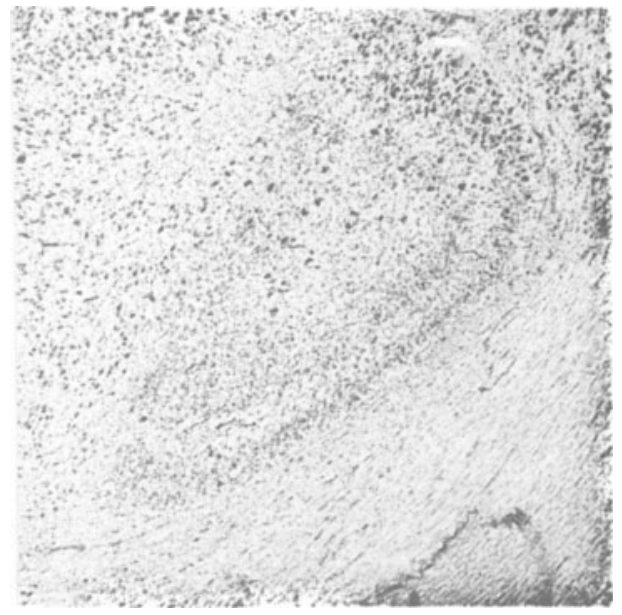

Fig. 1. LGN retrograde degeneration in $\mathrm{S} 2-4$.
Since a high mortality rate occurred in Group VK immediately following surgery and in Groups VK and NK as a result of laboratory diseases at 1 to 2 months of age, the following procedures were undertaken in an attempt to increase the survival of infant Ss. Surgery was performed only on the largest kittens in each litter, and litters 1,3 and 4 spent several weeks in the homes of laboratory personnel. Except for selection of Ss for operation, every effort was made to insure that operated and unoperated littermates were treated alike.

Surgery, performed aseptically, involved cortical removal of Visual I and II by means of subpial aspiration. Adults were injected intravenously with pentobarbital sodium anesthesia. Kittens were anesthetized intraperitoneally with $20 \mathrm{mg} / \mathrm{kg}$ doses supplemented with local application of procaine. Infants were 7-9 days old, and adults were at least $1 \mathrm{yr}$. old at the time of operation.

For histological analysis, Ss were perfused with $0.9 \%$ saline followed by $10 \%$ formalin. Brains were stored in formalin, embedded in celloidin, and sectioned at $30 \mu$. Every 20th section through the lesion and every 5th section through the dorsal lateral geniculate nuclei (LGN) were stained with cresyl violet and studied to determine the extent of retrograde degeneration.

\section{Experiment I Procedure and Results}

Only Groups VK and NK participated in activity and visual placing tests. At age 60-70 days, activity test I was conducted in a 4 by $4 \mathrm{ft}$ field. The floor consisted of 1 by $1 \mathrm{ft}$ alternate black and white square checked patterns. Black dowels vertically placed at all corners of the squares prevented corner crossings. Ss were randomly placed on one of the four center squares, and all movements were recorded $8 \mathrm{~min} . /$ day for 9 days. At age 102-113 days, activity test II was begun. Ss were placed in the same apparatus under the same conditions. At the end of $5 \mathrm{~min}$., lights under the quadrant upon which $\mathrm{S}$ was standing and lights under the diagonally opposite quadrant were turned out. Then activity was recorded for $4 \mathrm{~min}$. In the first activity test, Group VK did bump into walls and dowels more often than Group NK ( $p<.026)$. Otherwise, no differences

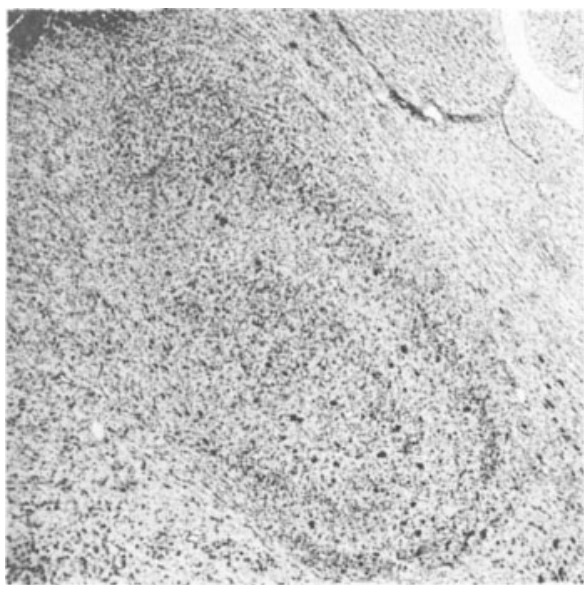

Fig. 2. LGN retrograde degeneration in S 4-9. 
were observed between the two groups in either test.

Visual placing responses were tested from time to time after Groups VK and NK were 56 days old. All kittens showed some visual placing reactions, and, from the tests conducted at irregular ages and intervals, the VK and NK groups could not be distinguished.

\section{Experiment II Procedure}

Infant and adult groups were tested for pattern discrimination learning in a Yerkes-Watson-Munn apparatus. When training began at age 120-132 days, only five normal and five visually lesioned kittens had survived laboratory illnesses. The striped vs. checked pattern discriminanda were identical to those of Meyer (1963), but training procedures differed slightly. After four to six days' apparatus adaptation, Ss were run 10 trials a day using the correction procedure. Stimuli were alternated according to a modified Gellerman series. Checked stimuli were positive for approximately half the Ss in each group. If Ss did not reach criterion of 9/10 correct responses within 500 trials, training was terminated. Reinforcement, $1.5 \mathrm{gm}$ of fish, was placed behind both positive and negative discriminanda to control for olfactory cues. A noise generator with a 72-db SPL output served to mask extraneous sounds.

\section{Results and Diseussion}

Histological analysis of the kitten LGNs revealed either localized sparing of large principal cells as illustrated in Fig. 1 in $\mathrm{S} \mathrm{2-4}$ or the absence of these cells as shown in Fig. 2 in S 4-9. Nevertheless, in all kittens, the 3 LGN laminae contained small, fainter staining, normal cells. S4-9 received the most extensive lesion as indicated by heavy gliosis and lack of principal cells, but a cluster of large cells was noted in layer $B$ of the left posterior LGN. The detailed histological analysis for Group VC will be reported in another article. Even though the five Ss in Group VK were matched with five of the eight Ss in Group VC for amount and locus of retrograde degeneration in the LGNs, the operated kittens were superior to these adults in pattern learning. In fact, two adult Ss with at least $50 \%$ of the LGNs spared were not able to learn the task within 500 trials. On the other hand, two kittens with comparable sparing learned the habit in 41 and 104 trials.

Learning scores for the pattern discrimination was

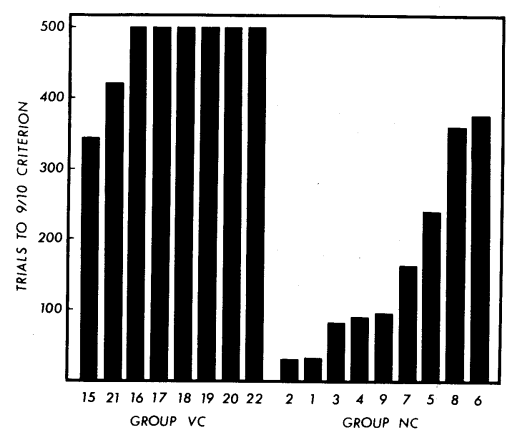

Fig. 3. Pattern discrimination learning for normal and operated cats.

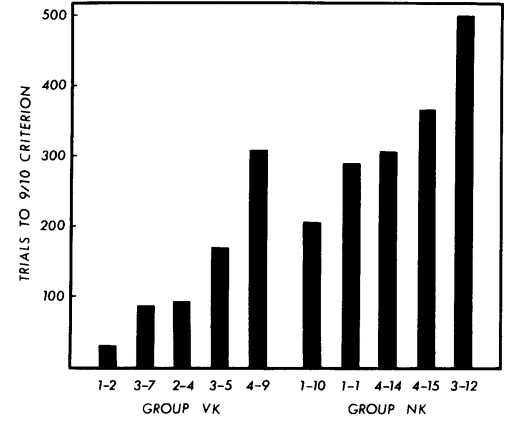

Fig. 4. Pattern discrimination learning for normal and operated kittens.

shown in Figs. 3 and 4 . Adult cats with visual lesions, as expected, did not learn the pattern habit within 500 trials, but the infant kittens with similar lesions learned as rapidly as normal adults. However, we did not expect the lesioned infants to be somewhat superior to their normal littermates $(p<.056)$. It is, of course, possible that this difference resulted from selecting for surgery only the largest kittens, who might have been more mature at time of testing than their normal littermate controls. Nevertheless, this experiment confirms other investigations that have found that the effects of brain damage in infancy are not nearly so severe as the consequences of lesions inflicted upon adult animals.

\section{References}

Akert, K., Orth, O. S., Harlow, H. F., \& Schlitz, K. A. Learned behavior of rhesus monkeys following neonatal bilateral prefrontal lobotomy. Science, 1960, 132, 1944-1945.

Benjamin, R. M., \& Thompson, R. F. Differential effects of cortical lesions in infant and adult cats on roughness discriminations. Exp. Neurol., 1959, 1, 305-321.

Doty, R. W. Functional significance of the topographical aspects of retino-cortical projection. In. J. Jung and H. Kornhaber (Eds.), The visual system: neurophysiology and psychophysics. Berlin: Sprinzer-Verlag, 1961. Pp. 228-247.

Horel, J. A., Bettinger, L. A., Royce, J. G., \& Meyer, D. R. Role of neocortex in the learning and relearning of two visual habits by the rat. J. comp. physiol. Psychol., in press.

Kennard, M. A. Cortical reorganization of motor function. Studies on a series of monkeys of various ages from infancy to maturity. Arch. neurol. Psychiat., 1942, 48, 227-240.

Lashley, K. S. Intregrative functions of the cerebral cortex. Physiol. Rev., 1933, 13, 1-42.

Meyer, P. M. Analysis of visual behavior in cats with extensive neocortical ablations. J. comp. physiol. Psychol., 1963, 56, 397-401.

Sharlock, D. P., Tucker, T. J., \& Strominzer, N. L. Auditory discrimination by the cat after neonatal ablation of the temporal cortex. Science, 1963, 141, 1197.

Smith, K. U. Visual discrimination in the cat: VI. The relation between pattern vision and visual acuity and the optic projection centers of the nervous system. J. genet. Psychol., 1938, 53, 215-272.

\section{Notes}

1. This investigation was supported by grant $\mathrm{MH}-06211$ from the National Institutes of Health.

2. Now at Department of Psychiatry, Stanford University Medical Center, Palo Alto, California.

3. Now at Neurosurgical Research Laboratory, Chicago Wesley Memorial Hospital, Chicago, Illinois.

4. Now at Department of Anatomy and Center for Neurobiological Sciences, College of Medicine, University of Florida, Gainesville, Florida. 